Лыков А.Ю.

\title{
МЕЖДУНАРОДНОЕ СООБЩЕСТВО КАК СТАДИЯ ПОЛИТИКО-ПРАВОВОЙ ЭВОЛЮЦИИ
}

\begin{abstract}
Аннотация. Статья анализирует проблему определения международного сообщества как современной стадии политико-правовой эволючии. Большинством исследователей используется понятие международного сообщества, однако его содержание и терминологическое определение не получили комплексного раскрытия в юридической науке вплоть до настоящего момента. Проведенный анализ позволяет сформировать признаки и определение указанного понятия. Раскрываются основные черты международного сообщества, позволяющие выделить его в качестве самостоятельного этапа общеизивилизационного развития. Анализ предмета исследования подкрепляется эмпирическими данными и осуществляется по средством соииокультурного метода. Содержащиеся в статье выводы и положения качественно расширяют и дополняют сферу научного познания в области теории государства и международных отномений. Выводы, изложенные в статье, могут быть использованы в международной правотворческой и правоприменительной практике.
\end{abstract}

Ключевые слова: Международное право, международный, сообщество, интеграчия, государство, договор, право, информационный, эволючия, глобальньий

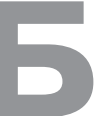

ольшинством юристов теоретиков государства и специалистов в сфере международных отношений используется понятие международного сообщества, однако его содержание и терминологическое определение не получили раскрытия в юридической науке вплоть до настоящего момента. Проведенный анализ позволяет сформировать признаки и определение указанного понятия, а также выявить существенные взаимосвязи рассматриваемого политико-правового явления.

Чтобы дать характеристику международного сообщества необходимо определить политически-организованное общество . Причина проста. Политически организованное общество - это родовое понятие. Международное сообщество является видом этого рода.Политически-организованное общество является совокупностью всех социальных организмов, на которые разделено человечество. Его эволюция проходит два этапа развития: этап регионального общения людей и этап всемирного человеческого взаимодействия. Первый из указанных этапов заканчивается совокупностью государств, как элементов политически-организованного общества и характеризуется невысоким уровнем информационного, экономического, политического и других видов взаимосвязей. Второй из указанных этапов начинается с преобразования совокупности государств в международное сообщество, отличающееся качественно новыми признаками и уровнем взаимодействия.

Изначально термина международного сообщества не существовало. Впервые возник термин «мировое сообщество», который был введен X. Буллом. Последний под мировым сообществом понимал не просто международную систему макросубъектов, но и правильную модель их поведения, которой они руководствуются при взаимодействии друг с другом ${ }^{1} . \mathrm{C}$ такой позиции мировое сообщество есть совокупность всех стран, независимо от уровня их развития, взаимодействие которых подчиняется определенным обычаям и правиламмеждународных отношений, формируемых историческим процессом политики национальных государств. В. С. Малахов также разделяя термины «международное сообщество»и «мировое сообщество» указывает,

\footnotetext{
${ }^{1}$ CM.: Bull H. The Anarchical Society: A Study of Order in World
} Politics. N.Y., 1995. P. $13-21$. 
что первое включает в себя все существующие государства, когда второе - только государства, которые демонстрируют приверженность к определенному кодексу поведения ${ }^{2}$.

Международное сообщество в отличие от мирового сообщества, предложенного $\mathrm{X}$. Буллом имеет другое значение и понимается специалистами в нескольких смыслах. Во-первых, как совокупность общественных отношений, существующих и регулируемых за пределами национальных правопорядков, представляющих сложную систему многообразных связей на межгосударственном уровне.Во-вторых, в виде совокупности государств, межгосударственных объединений, международных организаций, являющихся субъектами международного права и устанавливающих между собой политические, экономические, правовые и иные отношения.

Р. Уокер выделял следующие признаки международного сообщества. ${ }^{3}$ Во-первых, в нем отсутствует имперская власть, но допускаются гегемоны. Во-вторых, «никаких религиозных войн», так как последние рассматриваются как элементы «до-международного»- менее цивилизованного порядка. В-третьих, политическое существует только внутри государства и не переносится на международную арену. В-четвертых, в пределах международного сообщества нет места «варварам», то есть исключаются те, кто признается «неорганичным», не принадлежащим этому пространству4.

Представляется, что международное сообщество есть более развитый этап политически-организованного общества, возникающий после эволюции совокупности множества государственных образований, характери-

\footnotetext{
${ }^{2}$ Малахов В.С. Государство в условиях глобализации: учеб. пособие. М., 2007. С. 111.

${ }^{3}$ См.: Walker R.B.J. Inside/Outside: International Relations as Political Theory. Cambridge, 1993.

${ }^{4}$ Макарычев А.С. Международное сообщество, глобализация и безопасность / Международное сообщество и глобализация угроз безопасности: сб. науч. докладов. Ч. 2. Международное сообщество и национальные государства в поиске ответов на новые угрозы безопасности / отв. ред. В.В. Грохотова, Б.Н. Ковалев, Е.А.Макарова. В. Новгород, 2008. C. 13.
}

зующийся качественным изменением роли интеграционных процессов и быстрым информационным взаимодействием между различными государствами.

Несмотря на то обстоятельство, что ранее существовали взаимодействия между различными политическими объединениями, выделение международного сообщества как самостоятельной стадии развития социальной эволюции человека возможно только со второй половины XX века, так как в указанное время появляются особенности человеческого существования, ранее отсутствующие в развитии общества 5 . Его зарождение связывается со становлением ООН в 1945 году, Европейского объединения угля и стали в 1951 году, НАТО в 1949 году и других организаций.

Спорным является предположение, что международное сообщество возникло в первой четверти XX века с момента учреждения Лиги наций и СССР, или в целом с конца XIX века, как иногда фиксируется в исторической литературе. Несомненно, учреждение СССР и Лиги наций свидетельствует о появлении интеграционных процессов, но данный этап развития человечества является этапом индустриальных обществ и внешние отношения обусловливались либо политикой, либо экономикой. Это время характеризуется скорее интернационализацией, выражающейся во взаимодействии социальных общностей не в мировом масштабе, а на уровне группы отдельных стран ${ }^{6}$.

Международное объединение возможно только в рамках глобального информационного общества и высокого технологического уровня. Н. Лухман в связи с этим указывает следующее. Различные общества существуют в том случае, когда коммуникация между

\footnotetext{
${ }^{5}$ Мунтян М.А. Глобализация как вектор мирового развития: теоретические аспекты // Глобализация и проблемы развития Российской Федерации: матер.науч. конф. Ч. 2. М., 2002. С. 5-19; Зеленов Л.А., Владимиров А.А., Степанов Е.И. Современная глобализация: состояние и перспективы. М., 2010. С. 121; Купин В.Н. Глобальный империализм и геополитика // Ленинская теория империализма и современная глобализация: сб. Кн. 2. СПб., 2003. С. 305-307.

${ }^{6}$ Население и глобализация / Н.М. Римашевская, В.Ф. Галеиякий, А.А. Овсянников и др. М., 2004.С. 8.
} 
ними редка и ограничена. Поскольку в современном мире все общества связаны между собой все более интенсивными потоками различного рода коммуникаций, мы можем говорить о существовании глобального общества7.

Признаки международного сообщества характеризуются не столько появлением принципиально новой специфики политико-правовой организации, сколько существенным качественным изменением ранее существующих институтов. При этом принципиальной предпосылкой для таких качественных изменений служит мощный технологический и информационный скачок. Таким образом, можно выделить следующие признаки и особенности международного сообщества.

Во-первых, это совокупность субъектов, оказывающих влияние на международную политико-правовую действительность. При этом следует сделать оговорку, что субъекты международного сообщества отличаются от субъектов международного права. Под последними специалисты международного права, как правило, понимают участников международных отношений, которые в силу международно-правовых норм может выступать носителем субъективных прав и обязанностей. Любой субъект международного права обладает международной правоспособностью, дееспособностью и деликтоспособностью. Не все субъекты международного сообщества отвечают указанным критериям. Потому предлагается использовать собственную классификацию, согласно которой субъектов международного сообщества условно можно разделить на макросубъектов и микро субъектов. К последним относятся индивидуумы, небольшие частные и государственные образования. К макросубъктам относятся государства, международные организации, а также крупные транснациональные компании (далее - THK $)^{8}$.

\footnotetext{
${ }^{7}$ Luhmann N. The world society as a social system // Essays on self-reference. N.Y., 1990. P. 175-190.

${ }^{8}$ См.: Мунтян М.A. Идеология глобализма и современный мир // Идеология в современном обществе: Матер.круглого стола. М., 2002. С. 46-72.
}

Например, Роберт О. Кохэн подчеркивал, что в современных международных отношениях помимо государств действуют и крупные частные трансграничные организации. Сами ТНК в своей деятельности могут опираться и на государства-нации (например, Японская Sony) ${ }^{9}$. Так как ТНК участвуют в перераспределении экономических ресурсов, а последние, в том числе, являются предметом политического регулирования, а значит, решения указанных частных компаний, несомненно, могут носить международно-политический характер ${ }^{10}$.

Вместе с тем стоит согласиться, что роль ТНК достаточно противоречива: с одной стороны они мотор экономического развития (инвестиции, рабочие места, новые технологии), с другой - распространяют практику сверхэксплуатации по всей планете ${ }^{11}$.Улучшая атмосферу трудовых отношений в странах третьего мира, способствуя распространению более прогрессивных условий труда, ТНК также помогают удержаться у власти авторитарным режимам, поскольку последние позволяют контролировать уровень заработной платы ${ }^{12}$.

Однако, на наш взгляд, в научной литературе ТНК предписывается слишком много роли в мировой интеграции ${ }^{13}$. Ни кто не оспаривает укрупнение частного капиталистического сектора, но данный процесс является следствием развития общечеловеческой закономерности, а не причиной установления гегемонии какой-либо части населения.

Кроме того, международным сообществом в общечеловеческих целях могут применяться такие международно-правовые меры как эм-

\footnotetext{
${ }^{9}$ Малахов В.С. Государство в условиях глобализации. С. 87.

${ }^{10}$ Джозеф C., Роберт О.К. Транснациональные отношения и мировая политика // Теория международных отношений: хрестоматия / ред. П.А. Цыганков. М., 2003. С. 151-163; Современные глобальные проблемы: учеб.пособие / ред. А.С. Дундич. М., 2010. С. 15; Мунтян М.А. Идеология глобализма и современный мир С. 46-72.

${ }^{11}$ Stiglitz J.E. Making Globalization Work.N.Y., 2006.P. 192-196.

${ }^{12}$ Малахов В.С. Государство в условиях глобализации. С. 91.

${ }^{13}$ См. например: Эйфари А.К., Манцеев В.В. С. 7-9, С. 39; Современные глобальные проблемы. С. 62; Глобальные трансформации: Политика, экономика, культура / Д. Хелд, Д. Гольдблатт, Э. Макгрю и др. М., 2004. С. 64.
} 
барго, которые невозможны без их с применения непосредственно частными корпорациями (за исключением стран социалистической ориентации). Некоторые экономики стран (к их числу относится и российская) напрямую зависят от международного рынка ресурсов, в том числе нефти. Очевидно, что указанный рынок состоит преимущественно из компаний частного сектора. В 2007 году экспорт трансграничных корпораций составлял одну треть мирового экспорта ${ }^{14}$. При этом в таких сферах как энергетика действуют в основном только крупные частные корпорации. Среди них, как было указано в Financial Times, сформировались семь лидеров: Saudi Aramco из Саудовской Аравии, Российский «Газпром», Китайская национальная нефтяная корпорация (CNPC), Национальная иранская нефтяная компания (NIOC), венесуэльская PDVSA, бразильская Petrobras и малайзийская Petronas ${ }^{15}$.

С долей поправок, субъектом международного сообщества являются и нелегальные объединения, способные так или иначе влиять на вектор его развития ${ }^{16}$. После событий 11 сентября 2001 года в США достоянием гласности стала неблаговидная деятельность некоторых частных банков, на счетах которых накапливались средства, используемые международными террористическими организациями, в частности «Аль-Каидой» ${ }^{17}$. Например, только легальные поступления от процентов на вложенные в банки «отмытые» депозиты, вырученные за счет торговли наркотиками, приносят 65 млн. долларов США прибыли ежеминутно ${ }^{18}$. Организованная преступность, пишет немецкий исследователь К.Лаутербург, сегодня наиболее значительная «отрасль» экономики во всем мире, ее

\footnotetext{
${ }^{14}$ Современные глобальные проблемы. С. 70.

${ }^{15}$ Современные глобальные проблемы . С. 221.

${ }^{16}$ Кокошин А.А. Политика национальной безопасности России в условиях глобализации: краткий очерк. М., 2001. С. 4-6; Современные глобальные проблемы. С. 15.

${ }^{17}$ Современные глобальные проблемы. С. 16.

${ }^{18}$ Пряхин В.Ф. Как выжить? Новая идеология для человечества. М., 2008. С. 40.
}

годовой оборот оценивается сотнями миллиардов долларов ${ }^{19}$.

Основными субъектами международного сообщества остаются государства и международные организации, так как именно они принимают решения, которые становятся императивными для всех остальных в рамках их компетенции. При этом надгосударственные и международные структуры и организации приобретают все более значимый вес в глобальной политике по сравнению с национальными государствами ${ }^{20}$. Государство теряет свои регуляторские способности ${ }^{21}$.

Национальная власть перераспределяется не только в сторону наднациональных структур, но и на локальный (местный) уровень, который в международном сообществе по степени автономии становится тождественным национальным государствам, что приводит к размыванию политической независимости или разрушению государственного суверенитета ${ }^{22}$.

В таких политических системах как НАТО или Европейский Союз, политическая независимость входящих в их состав государств серьезно ограничена уже сейчас (как пример, меры, принятые в отношении Греции Евросоюзом в начале 2012 года). Если тенденции к объединению европейских стран продолжат двигаться в том же русле, то можно будет говорить о полной утрате их

\footnotetext{
${ }^{19}$ Пряхин В.Ф. Как выжить? Новая идеология для человечества. C. 4; Lauterburg C. Ftinf nach zwolf: der globale Crash und die Zakunft des Lebens. N.Y., 1998. P. 134.

${ }^{20}$ Хейвуд Э. Политология. М., 2005. С. 157; Мунтян М.А. Мировая политика и полилог цивилизаций как явления постмеждународного мира. URL: http://viperson.ru/data/200702/ (дата обращения 27. 02. 2013); Зеленов Л.А. и др. С. 44, 122 , $134 ;$ Глобализация и афро-азиатский мир: Методология и теория: реф.сб. / ред. Ю.И. Комар. М., 2007. С. 24.

${ }^{21}$ Wolf M. Why globalization works. Yale University Press, 2004. P. 252-260.

${ }^{22}$ Levine D.N. Sociology and the Nation-State in an Era of Shifting Boundaries // Readings in Globalization. Р. 159. Население и глобализация. С. 159; Глобальные конфликты нового и новейшего времени: учеб.пособие / ред. Н.В. Паниной. М., 2005. С. 113; Кревельд М. Расцвет и упадок государства. М., 2006. С. 9; Гезалов А.А. Трансформация общества в эпоху глобализации: Социально-философский анализ. М., 2009. С. 136; Глобальныетрансформации. С. 5.
} 
суверенитета и формировании нового единого субъекта. Ф. Фукуяма отметил по этому поводу, что «отказ европейцев от национального суверенитета в пользу наднациональной организации есть выражение их веры в конец истории» ${ }^{23}$.

Во-вторых, международное сообщество предполагает появление материальных возможностей для моментального информационного взаимодействия во всемирном масштабе 24. Ранее существовали международные отношения, но в силу технического развития массовых коммуникаций возможность моментального доведения сведений о принятии политически важных решений одного государства до населения другого стало возможным только начиная со второй половины ХХ века.

Информационные и коммуникационные процессы стали основой для целого ряда социально-теоретических концепций общества, заставляя переосмыслить отношение к таким фундаментальным понятиям, как пространство, время и действие ${ }^{25}$. Спутниковая связь сменила азбуку морза ${ }^{26}$. Стоимость трех минут телефонного разговора из Нью Йорка в Лондон сократилась с 1960 по 2000 год в 150 раз $^{27}$. К настоящему времени на Земном шаре отсутствуют изолированные подсистемы, т.е. страны или территории, которые не имеют ни экономических, ни политических, ни культурных связей с какой-либо другой территорией ${ }^{28}$.Международные отношения вышли на качественно новый уровень, при

\footnotetext{
${ }^{23}$ Fukuyama F. Has History Restarted Since September 11? // Centre for Independent Studies Occasional Paper. 2002. No. 81; Цит. по: Клаус В. Почему я не «европеист» / Европа без России: сб. / ред. А. Степанов. М., 2005. С. 15.

${ }^{24}$ Wriston W.B. The Twilight of Sovereignty: How the Information Revolution Is Transforming Our World. N.Y., 1992; Кревельд М. Расцвет и упадок государства. C. 480-481.

${ }^{25}$ Нозарчук A.B. Этика глобализирующегося общества: Тенденции и проблемы глобализации в свете социально-этической концепции К.О. Апеля. М., 2002. С. 207; McLuhan M., Powers B.R. The Global Village: Transformations in World Life and Media in the $21^{\text {st }}$ Century. Oxford, 1989. P. 103.

${ }^{26}$ Гидденс Э. Ускользающий мир: Как глобализация меняет нашу жизнь. М., 2004. С. 83.

${ }^{27}$ Глобализация и афро-азиатский мир. С. 27.

${ }^{28}$ Население и глобализация. С. 30.
}

котором общекультурные связи государств стали не просто взаимодействовать, а формировать единую взаимосвязанную систему ${ }^{29}$.

Теперь политико-правовое регулирование осуществляется все в большей степени с учетом межнационального уровня, и решение, касающееся внутренней политики, неизбежно зависит от его отражения всем международным сообществом ${ }^{30}$.Если министерство иностранных дел с давних пор отвечало, прежде всего, за все аспекты международных отношений и внешней политики, то теперь эта ответственность все более и более распределяется между различными министерствами и департаментами. Это повлекло за собой быстрое увеличение не только численности и разнообразия исполнителей, заключающих международные соглашения, но также числа и форм соглашений, заключаемых между государствами ${ }^{31}$.

В-третьих, международное сообщество характеризуется увеличением объема международного права ${ }^{32}$. Настоящее исследование не посвящено анализу этой «особой» правовой системы, разработка и изучение его проблематики которой осуществляется учеными-специалистами по международному праву. Здесь требуется обозначить лишь то обстоятельство, что в настоящее время сфера действия международного права значительно расширилась. Международные договоры, в случае коллизии имеют более высокую силу, чем внутреннее законодательство, что подтверждается не только в международных договорах, но и во многих национальных конституциях. Возросло как количество самих международных договоров и сфер правового регулирования, так и количество стран участников, для которых указанные правила являются обязательными.

\footnotetext{
29 Тойнби А.Д. Постижение истории. М., 1991. С. 34.

${ }^{30}$ См.: Ougaard M. Political Globalization: State, Power and Social Forces.L., 2004.P. 4-6; Hantington S.P. The Clash of Civilizations? / Readings in Globalization. Р. 24; Зеленов Л.А. и др. Указ.соч. С. 38; Глобальные трансформации. С. 1.

${ }^{31}$ Глобальные трансформации. С. 64.

${ }^{32}$ Гезалов A.A. Трансформация общества в эпоху глобализации С. 9-11.
} 
B-четвертых, на указанном этапе развития политически-организованного общества появляется новый уровень взаимозависимости экономических и культурных отношений ${ }^{33}$. Рост экономики одного государства или рост стоимости его валюты прямо коррелирует с экономическими показателями других государств.Популярная культура в одном месте неизбежно распространяется и на другие территории. Население везде использует одну технологию, слушает одну музыку и смотрит одни фильмы ${ }^{34}$. Массовая культура характеризуется не только появлением универсальных стандартов, но и, прежде всего, общедоступностью как стандартов, так и исключительных субкультур 35 . Поскольку контакты с представителями чужих культур перестают быть чем-то одноразовым, превращаясь в рутину, элементы этих культур постепенно становятся частью повседневности ${ }^{36}$. Одновременно с этим разрушаются государственные границы, прекращаются визовые режимы либо смягчается миграционный контроль ${ }^{37}$.

В-пятых, именно с приходом международного сообщества закрепляется система всемирной коллективной безопасности. Государства через систему совместных соглашений договариваются о предотвращении актов агрессии и ограничении вооружения. Ярким примером является Международный договор «О нераспространении ядерного оружия» от 5 марта 1970 года, согласно которому каждая страна - участник договора, обладающая ядерным оружием, обязуется не распространять его или другие ядерные

${ }^{33}$ Кастельс М. Информационная эпоха: Экономика общества и культура. М., 2000. С. 105.

${ }^{34}$ Глобальные трансформации. С. 413-418.

${ }^{35}$ Многоликая глобализация: культурное разнообразие в современном мире / под.ред. П.Л. Бергера, С.П. Хантингтона. М., 2004. С. 65-66; Глобализация и афро-азиатский мир. С. 51.

${ }^{36}$ Robertson R. Globalization: Social Theory and Global Culture. L., 1992.P. 58-60.

37 Добреньков В.И. Глобализация и Россия // Будущее России: стратегии развития: матер.науч. конф. «Ломоносовские чтения. 2005»: сб. Т.1. М., 2005. С. 3; McGrew A. Globalization and Global Politics // The Globalization of World Politics. N.Y., 2005. P. 23-25; устройства, в том числе не передавать его прямо или косвенно, а также не помогать и не поощрять какое-либо государство, не обладающее ядерным оружием к производству или приобретению каким-либо иным способом ядерного оружия или других ядерных взрывных устройств, а также контроля над ними.

Кроме того, согласно Резолюции Совета Безопасности ООН от 19 июня 1968 года, в случае нападения или угрозы ядерного нападения на неядерное государство, страны, которые обладают ядерным вооружением, обязуются немедленно действовать для защиты атакованного государства ${ }^{38}$. При этом система всемирной коллективной безопасности подкрепляется и региональными договорами о поддержании безопасности. Например, в рамках российского и китайского участия в Центральной Азии были созданы Организация договора о коллективной безопасности (ОДКБ) и Шанхайская организация сотрудничества (ШОС) ${ }^{39}$. Первой организацией в 2009 году были учреждены Коллективные силы оперативного регулирования для недопущения насильственных актов экстремизма, целью последней стала борьба с терроризмом, сепаратизмом и экстремизмом ${ }^{40}$.

В-шестых, международное сообщество предполагает наличие международных судебных органов. Например, Международный суд по правам человека, Международный суд ООН. Специфика, структура и работа указанных судебных органов является предметом самостоятельного научного исследования, однако важен факт, что судебные органы вышли за пределы каузального и регионального уровня и действуют в масштабах всего международного сообщества. В результате

\footnotetext{
${ }^{38}$ Новиков А.А. Планетарное государство - глобальная экономическая и социальная модель. - М., 2008.С. 64-65.

${ }^{39}$ Современные глобальные проблемы. С. 152; Alyson J.K., Bailes, P.D., Pan G. The Shanghai Cooperation Organisation // SIPRI Policy Paper. 2007. N17. URL: http://books.sipri.org/ product_info?c_product_id=338 (дата обращения 27.02.2013); Сафранчук И.А. Конкуренция за безопасность в Центральной Азии // Россия в глобальной политике. 2007. Ноябрь-декабрь. URL: http://www.globalaffairs.ru/numbers/29/8833. html (дата обращения 27.02.2013)

${ }^{40}$ Современные глобальные проблемы. С. 154.
} 
в научный и политический оборот начинает вводиться термин «транснациональная юстиция» («transnational justice»), который обозначает уже не только деятельность международных судов, рассматривающих дела государств, но гораздо более широкую сферу отношений: правосудие между отдельными людьми в рамках мирового сообщества. Иногда этот термин заменяется более амбициозным понятием «глобальная юстиция», в которую входят и на которую замыкаются все существующие уровни правосудия в мире ${ }^{41}$.

Наконец, с формированием международного сообщества закрепляется курс на совместное решение задач всеми странами и регионами Земного шара, в том числе разрешение правового регулирования глобальных проблем, предотвращение распространения оружия массового поражения, экологических, демографических, техногенных и других кризисов, появившихся в следствие биокультурной эволюции нашей планеты.

Таким образом, международное сообщество можно определить как этап развития полити- чески-организованного общества, характеризующийся появлением материальных возможностей для информационного взаимодействия во всемирном масштабе, увеличением объема и роли международного права, новым уровнем взаимозависимости экономических и культурных отношений, а также формированием всемирных систем коллективной безопасности, судебных органов и закреплением курса на совместное разрешение его участниками глобальных проблем и их правового регулирования.

Рассмотренные признаки не носят статичный характер, а качественно развиваются по заданному вектору развития, формируя при этом целостную концепцию международного сообщества. Соответственно при анализе дальнейших политико-правовых перспектив развития человечества необходимо исходить из выявленных существенных взаимосвязей,изученных в настоящей работе. Они могут служить теоретической основой для дальнейших фундаментальных исследований и применения в международной правотворческой и правоприменительной практике.

\section{Библиография:}

1. Bull H. The Anarchical Society: A Study of Order in World Politics. - N.Y., 1995.

2. Fukuyama F. Has History Restarted Since September 11? // Centre for Independent Studies Occasional Paper. - 2002. - N 81.

3. Levine D.N. Sociology and the Nation-State in an Era of Shifting Boundaries // Readings in Globalization: Key concepts and major debates, Blackwell Publishing / eds. G. Ritzer, Z. Atalay. - Oxford, 2010. - P. $159-160$.

4. Luhmann N. The world society as a social system // Essays on self-reference. - N.Y.: Columbia University Press, 1990. - P. 175 - 190.

5. McGrew A. Globalization and Global Politics // The Globalization of World Politics: An Introduction to International Relations / eds. J. Baylis, S. Smith, P. Owens. - N.Y., 2005. - P. $19-44$.

6. McLuhan M., Powers B.R. The Global Village: Transformations in World Life and Media in the $21^{\text {st }}$ Century. - Oxford, 1989.

7. Ougaard M. Political Globalization: State, Power and Social Forces. (International Political Economy). - L., 2004.

8. Stiglitz J.E. Making Globalization Work - N.Y.: W.W. Norton \& Company, 2006. (Reprint edition)

\footnotetext{
${ }^{41}$ Барабанов О. Глобальное управление как тема для научного анализа // Антиглобализм и глобальное управление: Доклады, дискуссии, справочные материалы / отв. ред. Д.Н. Песков. M., 2006. C. 26-27.
} 
9. Walker R.B.J. Inside/Outside: International Relations as Political Theory. - Cambridge, 1993.

10. Барабанов О. Глобальное управление как тема для научного анализа // Антиглобализм и глобальное управление. - М., 2006. - С. 12 - 31.

11. Гезалов А.А. Трансформация общества в эпоху глобализации: Социально-философский анализ. - М.: Канон+, 2009. - 288 с.

12. Гидденс Э. Ускользающий мир: Как глобализация меняет нашу жизнь. - М.: Весь Мир, 2004. - 116 c.

13. Глобальные конфликты нового и новейшего времени: учеб. пособие / под ред. Н.В. Паниной. - М.: МИЭМ, 2005. - 116 с.

14. Глобальные трансформации: Политика, экономика, культура / Д. Хелд, Д. Гольдблатт, Э. Макгрю и др. - М.: Праксис, 2004. - 575 с.

15. Джозеф С., Роберт О.К. Транснациональные отношения и мировая политика // Теория международных отношений: хрестоматия / сост. П.А. Цыганков. - М.: Гардарики, 2003. - С. $147-151$.

16. Добреньков В.И. Глобализация и Россия // Будущее России: стратегии развития: матер. науч. конф. «Ломоносовские чтения. 2005»: сб. В 2 т. Т.1. - М.: МАКС Пресс, 2005. C. $3-15$.

17. Зеленов Л.А. Современная глобализация: состояние и перспективы / Л.А. Зеленов, А.А. Владимиров, Е.И. Степанов. - М.: URSS, 2010. - 298c.

18. Кастельс М. Информационная эпоха: Экономика общества и культура. - M.: GEU, 2000. $-606 \mathrm{c}$.

19. Кокошин А.А. Политика национальной безопасности России в условиях глобализации: краткий очерк. - М.: ИПМБ РАН, 2001. - 68 с.

20. Кревельд М. Расцвет и упадок государства. - М.: ИРИСЭН, 2006. - 544c.

21. Купин В.Н. Глобальный империализм и геополитика // Ленинская теория империализма и современная глобализация: сб. Кн. 2. - СПб., 2003. - С. 305 - 307.

22. Макарычев А.С. Международное сообщество, глобализация и безопасность / Международное сообщество и глобализация угроз безопасности: сб. науч. докладов. Ч. 2. - В.Новгород, 2008. - C. $9-24$.

23. Малахов В.С. Государство в условиях глобализации: учеб. пособие. - М.: КДУ, 2007. - 256 с.

24. Многоликая глобализация: культурное разнообразие в современном мире / под. ред. П.Л. Бергера и С.П. Хантигтона. - М.: Аспект Пресс, 2004. - 378c.

25. Мунтян М.А. Глобализация как вектор мирового развития: теоретические аспекты // Глобализация и проблемы развития Российской Федерации: матер. науч. конф. Ч. 2 - М.: МВШ, 2002. - С. 5 - 19.

26. Население и глобализация / Н.М. Римашевская, В.Ф. Галецкий, А.А. Овсянников и др. М.: Наука, 2004. - 321 с.

27. Новиков А.А. Планетарное государство - глобальная экономическая и социальная модель. - М.: Спец-Адрес, 2008. - 87 с.

28. Нозарчук А.В. Этика глобализирующегося общества: Тенденции и проблемы глобализации в свете социально-этической концепции К.О. Апеля. - М.: Директмедиа паблишинг, 2002. -378 c.

29. Пряхин В.Ф. Как выжить? Новая идеология для человечества. - М.: Весь Мир, 2008. - 142 с.

30. Современные глобальные проблемы: учеб. пособие / ред. А.С. Дундич. - М.: Аспект Пресс, 2010. -348 c.

31. Тойнби А.Д. Постижение истории. - М.: Прогресс, 1991. - 730 с.

32. Хейвуд Э. Политология: учебник. - М.: Юнити, 2005. - 525 с.

33. Эйфари А.К. Глобализация и развивающиеся страны (политэкономический аспект) / А.К. Эйфари, В.В. Манцев. - М: РУДН, 2007. - 62 с. 


\section{References (transliteration):}

1. Bull H. The Anarchical Society: A Study of Order in World Politics. - N.Y., 1995.

2. Fukuyama F. Has History Restarted Since September 11? // Centre for Independent Studies Occasional Paper. - 2002. - N 81.

3. Levine D.N. Sociology and the Nation-State in an Era of Shifting Boundaries // Readings in Globalization: Key concepts and major debates, Blackwell Publishing / eds. G. Ritzer, Z. Atalay. - Oxford, 2010. - P. $159-160$.

4. Luhmann N. The world society as a social system // Essays on self-reference. - N.Y.: Columbia University Press, 1990. - P. 175 - 190.

5. McGrew A. Globalization and Global Politics // The Globalization of World Politics: An Introduction to International Relations / eds. J. Baylis, S. Smith, P. Owens. - N.Y., 2005. - P. $19-44$.

6. McLuhan M., Powers B.R. The Global Village: Transformations in World Life and Media in the $21^{\text {st }}$ Century. - Oxford, 1989.

7. Ougaard M. Political Globalization: State, Power and Social Forces. (International Political Economy). - L., 2004.

8. Stiglitz J.E. Making Globalization Work - N.Y.: W.W. Norton \& Company, 2006. (Reprint edition)

9. Walker R.B.J. Inside/Outside: International Relations as Political Theory. - Cambridge, 1993.

10. Barabanov O. Global'noe upravlenie kak tema dlja nauchnogo analiza // Antiglobalizm i global'noe upravlenie. - M., 2006. - C. 12 - 31.

11. Gezalov A.A. Transformacija obshhestva v jepohu globalizacii: Social'no-filosofskij analiz. M.: Kanon+, 2009. - 288 s.

12. Giddens Je. Uskol'zajushhij mir: Kak globalizacija menjaet nashu zhizn'. - M.: Ves' Mir, 2004. $-116 \mathrm{~s}$.

13. Global'nye konflikty novogo i novejshego vremeni: ucheb. posobie / pod red. N.V. Paninoj. M.: MIJeM, 2005. - $116 \mathrm{~s}$.

14. Global'nye transformacii: Politika, jekonomika, kul'tura / D. Held, D. Gol'dblatt, Je. Makgrju i dr. - M.: Praksis, 2004. - 575 s.

15. Dzhozef S., Robert O.K. Transnacional'nye otnoshenija i mirovaja politika // Teorija mezhdunarodnyh otnoshenij: hrestomatija / sost. P.A. Cygankov. - M.: Gardariki, 2003. S. $147-151$.

16. Dobren'kov V.I. Globalizacija i Rossija // Budushhee Rossii: strategii razvitija: mater. nauch. konf. «Lomonosovskie chtenija. 2005»: sb. V 2 t. T.1. - M.: MAKS Press, 2005. - S. 3 - 15.

17. Zelenov L.A. Sovremennaja globalizacija: sostojanie i perspektivy / L.A. Zelenov, A.A. Vladimirov, E.I. Stepanov. - M.: URSS, 2010. - 298c.

18. Kastel's M. Informacionnaja jepoha: Jekonomika obshhestva i kul'tura. - M.: GEU, 2000. - $606 \mathrm{~s}$.

19. Kokoshin A.A. Politika nacional'noj bezopasnosti Rossii v uslovijah globalizacii: kratkij ocherk. - M.: IPMB RAN, 2001. - $68 \mathrm{~s}$.

20. Krevel'd M. Rascvet i upadok gosudarstva. - M.: IRISJeN, 2006. - 544s.

21. Kupin V.N. Global'nyj imperializm i geopolitika // Leninskaja teorija imperializma i sovremennaja globalizacija: sb. Kn. 2. - SPb., 2003. - C. $305-307$.

22. Makarychev A.S. Mezhdunarodnoe soobshhestvo, globalizacija i bezopasnost' / Mezhdunarodnoe soobshhestvo i globalizacija ugroz bezopasnosti: sb. nauch. dokladov. Ch. 2. - V.Novgorod, 2008. - S. $9-24$.

23. Malahov V.C. Gosudarstvo v uslovijah globalizacii: ucheb. posobie. - M.: KDU, 2007. - 256 s.

24. Mnogolikaja globalizacija: kul'turnoe raznoobrazie v sovremennom mire/ pod. red. P.L. Bergera i S.P. Hantigtona. - M.: Aspekt Press, 2004. - 378s. 
25. Muntjan M.A. Globalizacija kak vektor mirovogo razvitija: teoreticheskie aspekty // Globalizacija i problemy razvitija Rossijskoj Federacii: mater. nauch. konf. Ch. 2 - M.: MVSh, 2002. - S. 5 - 19.

26. Naselenie i globalizacija / N.M. Rimashevskaja, V.F. Galeckij, A.A. Ovsjannikov i dr. - M.: Nauka, 2004. - $321 \mathrm{~s}$.

27. Novikov A.A. Planetarnoe gosudarstvo - global'naja jekonomicheskaja i social'naja model'. M.: Spec-Adres, 2008. -87 s.

28. Nozarchuk A.V. Jetika globalizirujushhegosja obshhestva: Tendencii i problemy globalizacii v svete social'no-jeticheskoj koncepcii K.O. Apelja. - M.: Direktmedia pablishing, 2002 - $378 \mathrm{~s}$.

29. Prjahin V.F. Kak vyzhit'? Novaja ideologija dlja chelovechestva. - M.: Ves' Mir, 2008. - 142 s.

30. Sovremennye global'nye problemy: ucheb. posobie / red. A.S. Dundich. - M.: Aspekt Press, 2010. $-348 \mathrm{~s}$

31. Tojnbi A.D. Postizhenie istorii. - M.: Progress, 1991. - 730 s.

32. Hejvud Je. Politologija: uchebnik. - M.: Juniti, 2005. - 525 s.

33. Jejfari A.K. Globalizacija i razvivajushhiesja strany (politjekonomicheskij aspekt)/ A.K. Jejfari, V.V. Mancev. - M: RUDN, 2007. - 62 s. 